\title{
Community-Based Participatory Research and Drug Utilization Research to Improve Childhood Diarrhea Case Management in Ujjain, India: A Cross-Sectional Survey
}

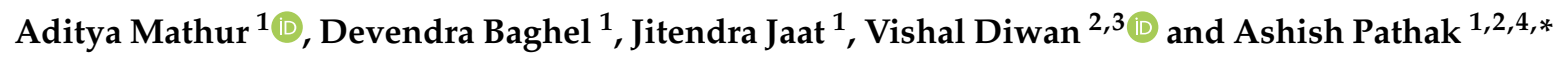 \\ 1 Department of Pediatrics, R. D. Gardi Medical College, Ujjain 456006, India; \\ dr.adityamathur121@gmail.com (A.M.); dbaghel201@gmail.com (D.B.); jitendrajat46@gmail.com (J.J.) \\ 2 Global Health-Health Systems and Policy, Department of Public Health Sciences, Karolinska Institutet, \\ SE-171 76 Stockholm, Sweden; vishaldiwan@hotmail.com \\ 3 Department of Public Health \& Environment, R. D. Gardi Medical College, Ujjain 456006, India \\ 4 Department of Women and Children's Health, International Maternal and Child Health Unit, \\ Uppsala University, SE-751 85 Uppsala, Sweden \\ * Correspondence: ashish.pathak@kbh.uu.se or drashish.jpathak@gmail.com; Tel.: +91-930-223-9899
}

Received: 17 April 2019; Accepted: 9 May 2019; Published: 11 May 2019

\begin{abstract}
Childhood diarrhea continues to be a major cause of under-five (U-5) mortality globally and in India. In this study, 1571 U-5 children residing in nine rural villages and four urban slums in Ujjain, India were included with the objective to use community participation and drug utilization research to improve diarrheal case management. The mean age was 2.08 years, with $297(19 \%)$, children living in high diarrheal index households. Most mothers (70\%) considered stale food, teething $(62 \%)$, and hot weather $(55 \%)$ as causes of diarrhea. Water, sanitation, and hygiene (WASH)-related characteristics revealed that most (93\%) households had toilets, but only $23 \%$ of the children used them. The study identified ineffective household water treatment by filtration through cloth by most (93\%) households and dumping of household waste on the streets $(89 \%)$. The results revealed low community awareness of correct causes of diarrhea (poor hand hygiene, $21 \%$; littering around the household, 15\%) and of correct diarrhea treatment (oral rehydration solution (ORS) and zinc use, 29\% and $11 \%$, respectively) and a high antibiotic prescription rate by healthcare providers (83\%). Based on the results of the present study, context-specific house-to-house interventions will be designed and implemented.
\end{abstract}

Keywords: Child; diarrhea; water sanitation and hygiene; rehydration solution; zinc; case management; antibacterial agents; drug utilization; community participation; India

\section{Introduction}

Globally, diarrhea continues to be one of the major causes of mortality among children aged less than five years [1,2]. India as a country, has the highest number of childhood deaths due to diarrhea with 400,000 deaths annually [2]. Three states of India, including Madhya Pradesh (MP), account for nearly half of India's childhood diarrhea burden [3,4]. The majority of childhood diarrhea deaths $(80 \%)$ occur in rural areas, where informal healthcare providers (IHCPs) are the predominant providers [5]. Oral rehydration solution (ORS) and zinc use can prevent $69 \%$ of the mortality associated with diarrhea among children aged less than five years [2,5]. Despite this, treatment according to the relevant guidelines (i.e., ORS and zinc use) is provided only to $39 \%$ of children with diarrhea, but antibiotics are prescribed to $72 \%$ of these children [6]. Studies have suggested that improved case 
management including increasing the prescription of ORS and zinc and reducing that of antibiotics, addressing social determinants of health and research to identify cost-effective interventions, and promoting equitable access to interventions, is needed $[7,8]$. Some studies have examined healthcare workforces' knowledge, attitude, and practice toward diarrhea [9-11]. Studies performed in India have shown that parents' awareness of ORS is high ( $89 \%, 86.7 \%$, and $90.7 \%)$, but the practice of using ORS for diarrhea episodes is lower $(51 \%, 54.8 \%$, and $60 \%$ ) in comparison to awareness among parents; these results indicate a wide "know-do" gap [9-11].

The aims of this paper are to present data on community perceptions for causes of diarrhea, perceptions for diarrhea treatment, treatments given at home, health-seeking behavior for diarrhea, and the pattern of drug prescription by healthcare providers for diarrhea in the community. Based on this study, interventions would be planned to increase the ORS and zinc prescription rates in the community.

\section{Materials and Methods}

\subsection{Study Design and Setting}

This cross-sectional community-based study was conducted between June to August 2017. This survey was conducted in the Ujjain district. The Ujjain district is one of the 51 administrative districts in MP. The Ujjain district has a population of 1.9 million within an area of $6091 \mathrm{sq} . \mathrm{km} ; 61 \%$ of the district is rural [12]. A list of villages in the Ujjain district and slums in Ujjain city (the district headquarters) was made, and nine villages and four slums were randomly selected for the study.

\subsection{Sample Size Calculation}

For the sample size calculation, the ORS prescription rate was considered the primary outcome. It was assumed that each intervention would increase the ORS prescription rate by $15 \%$ at least. National Family Health Survey-4 (NFHS-4) data showed that the ORS prescription rate was 57\% in the Ujjain district [13]. Thus, assuming 0.57 as the proportion of healthcare providers prescribing ORS and assuming a 95\% confidence interval for this proportion with a width not higher than $15 \%$, the minimum sample size needed was calculated to be 172 children with diarrhea. The study was planned in nine villages and four slums, a conservative estimate of design effect of four was considered appropriate [14]; this gave a minimum sample size needed of 688 children $(172 \times 4)$.

\subsection{Sampling Frame and Data Collection Tools and Methods}

All households in each of the selected nine villages and four slums were manually listed to obtain a sampling frame of households. A total of 2830 households were surveyed to list households having children up to five years of age. A total of 1181 households were identified to have children up to five years of age. These households were further surveyed, and 1571 children were included in the study after obtaining informed consent from the family head.

All households in the sampling frame were visited. Mothers or caregivers (maternal or paternal grandmother/grandfather/aunt/uncle) were interviewed by trained data collectors and a predesigned questionnaire was filled-in to obtain information on their perceptions of the causes of diarrhea. Other questions explored their perceptions of treatment; number of diarrhea episodes experienced by their child in the last three months and treatment given for the last diarrhea episode at home. Questions assessed their awareness of ORS and zinc use; availability of ORS and zinc; feeding practices during diarrhea, and details on health-seeking behavior for the last diarrhea episode. The questionnaire collected information on household factors including education status of the mother, caste, religion, type of house, number of household members, and socioeconomic status. Information on water, sanitation, and hygiene (WASH)-related variables were also collected from each household.

The questionnaire was first prepared in English, then translated to Hindi, and back-translated by subject and Hindi language experts [15]. Any discrepancy was resolved by reaching a consensus. 
For assessing content and construct validity [15], the questionnaire was pilot tested on 50 respondents. Changes were made to three questions related to household WASH characteristics and health-seeking behavior for diarrhea, which had an intra-class correlation coefficient of less than 0.65 .

The proportion of children prescribed ORS and zinc, the timing of ORS and zinc initiation post diarrhea, and duration of ORS and zinc use was calculated through house-to-house surveys. The antibiotic prescribed for each diarrhea episode for a given child was also noted. To get an accurate account of antibiotic use in the previous episode of diarrhea, mothers/caregivers were asked to show the original prescriptions, package inserts and partly used packages of all drugs consumed. Further, the mothers were shown a picture of 20 commonly marketed antibiotic syrups. Injectable antibiotic use was ascertained by interviewing the formal and informal health care providers catering to the study population. If the mothers/caregivers could not identify the specific antibiotic using the above three methods, then such an incident was classified as "non-use" of antibiotic.

The diarrhea index was calculated by summing the number of diarrhea episodes in the previous three months among all children aged less than five years residing in a given household divided by the total number of children aged less than five years and multiplied by 100, as shown in the formula (1) below:-

$$
\text { Diarrhea index }=\frac{\sum a_{n}+b_{n}+c_{n}+d_{n}}{y} \times 100
$$

where,

1. $a_{n}=$ number of episodes of diarrhea in the past three months in the first child living in the same household.

2. $b_{n}=$ number of episodes of diarrhea in past three months in the second child living in the same household as a.

3. $c_{n}=$ number of episodes of diarrhea in the past three months in the third child living in the same household as a and $\mathrm{b}$.

4. $d_{n}=$ Number of episodes of diarrhea in the past three months in the fourth child living in the same household as a, b, and c

5. $y=$ Number of children aged less than five years living in the same household

Households with a diarrhea index of 200 or more were considered to be households with a high diarrhea index (HDI). The cut-off for HDI was decided post-hoc based-on the results of the study. All HDI households are the targets of community-based interventions to improve diarrhea case management in the future.

\subsection{Data Management and Data Analysis}

The data was collected on the paper-based questionnaire. A database was created using Epidata 3.1 (The EpiData Association, Odense, Denmark). Data entry was performed by trained research assistants and was supervised by senior researchers. All data entered were double-checked for quality assurance. All continuous variables that follow a normal Gaussian distribution were presented as mean \pm standard deviation. All categorical variables were summarized and expressed as proportions. Data analyses were performed using Stata (Version 13.0, Statacorp., College Station, TX, USA).

\subsection{Ethical Consideration}

This study was approved by the Institutional Ethics Committee (IEC) of the R.D. Gardi Medical College, Ujjain, India (Approval number: IEC/RDGMC/493). Informed consent was obtained from participants before the interview. Participants had the right to withdraw from the study at any time.

\subsection{Availability of Data and Materials}

Due to ethical and legal restrictions, all inquiries should be made to The Chairman, Ethics Committee, R.D. Gardi Medical College, Agar Road, Ujjain, India 456006 (E-mails: iecrdgmc@yahoo.in, 
uctharc@sancharnet.in), giving full details of the intended use. Upon verification of genuineness of the inquiry, the data that will be generated from various studies of this protocol will be made available. For reference, please quote the ethical permission number: 2016/01/18-493.

\section{Results}

A total of 2830 households were approached and 1181 households, which had children below five years of age, were included in the study. From the 1181 households, 1571 children were included, with 815 boys and 756 girls. A total of 858 children belonged to rural areas, and 713 were from urban slums. The selection of study participants and their distribution according to low and high diarrheal index households is depicted in Figure 1. In the study area, 17 formal and 43 informal healthcare providers are present, which were often the first point of contact for healthcare-seeking for the community. Mothers were the main caregivers in the majority $(99.6 \%)$ of households.

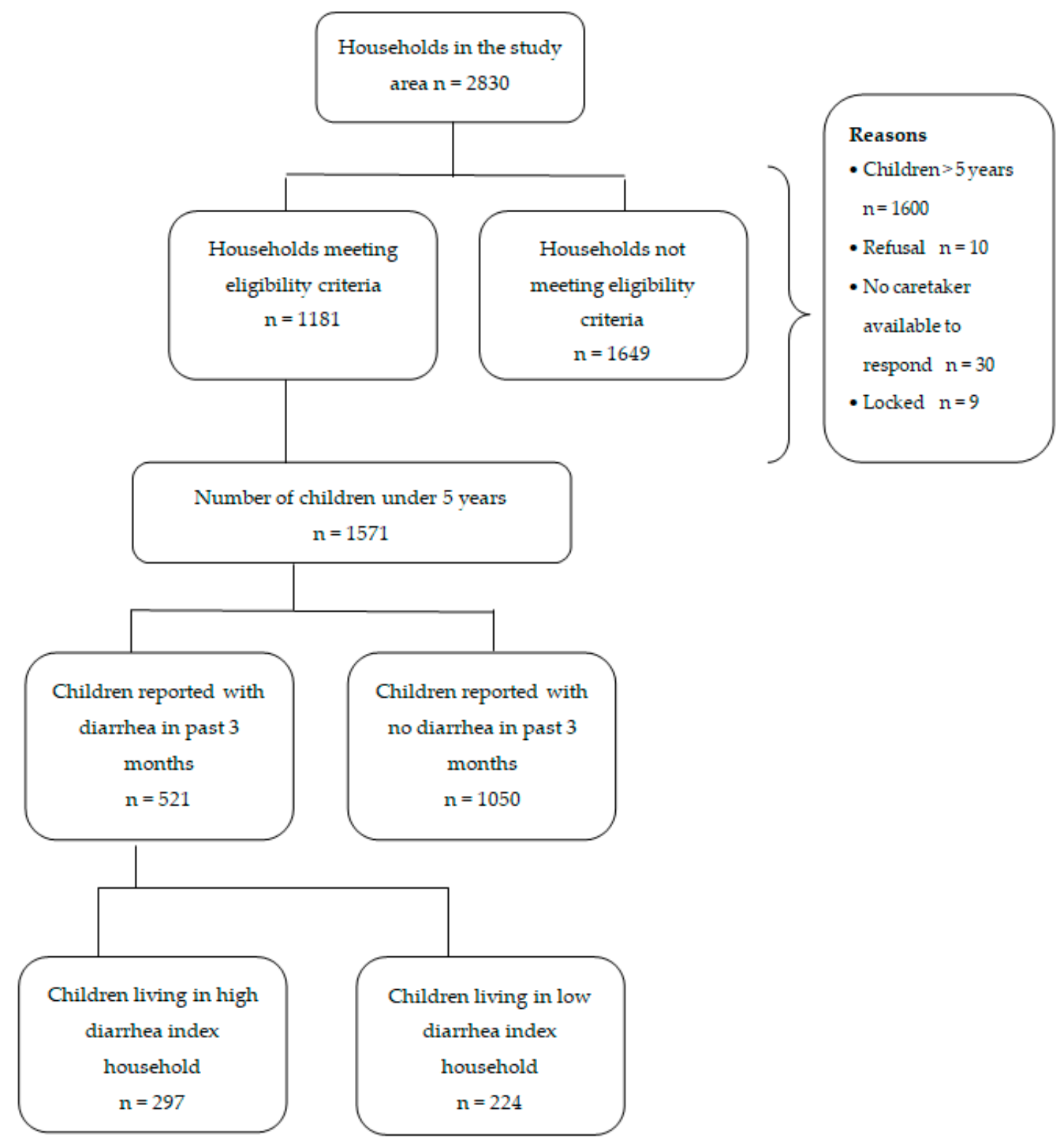

Figure 1. Process of selection of the study participants and their distribution according to low and high diarrheal index households in the study. 
Table 1 provides the socio-demographic characteristics of the study participants.

Table 1. Socio-demographic characteristics of 1181 households having 1571 children included in the survey.

\begin{tabular}{|c|c|c|}
\hline Socio-demographic characteristics. & Mean & SD \\
\hline \multicolumn{3}{|l|}{ Continuous variables } \\
\hline Age of the children (years) & 2.08 & 1.18 \\
\hline Family size (number) & 7.20 & 3.24 \\
\hline Age of mother (years) & 25.11 & 4.67 \\
\hline Categorical variables & $n=1181$ households & $\%$ \\
\hline \multicolumn{3}{|l|}{ Location } \\
\hline Rural & 660 & 56 \\
\hline Urban & 521 & 44 \\
\hline \multicolumn{3}{|l|}{ Education status of mother } \\
\hline Uneducated & 240 & 20 \\
\hline Primary & 629 & 53 \\
\hline Secondary or more & 312 & 27 \\
\hline \multicolumn{3}{|l|}{ Caste } \\
\hline General & 151 & 13 \\
\hline Scheduled castes * & 166 & 14 \\
\hline Scheduled tribes * & 815 & 69 \\
\hline Other backward class * & 49 & 4 \\
\hline \multicolumn{3}{|l|}{ Religion } \\
\hline Hindu & 695 & 59 \\
\hline Muslim & 460 & 39 \\
\hline Others & 26 & 2 \\
\hline \multicolumn{3}{|l|}{ Type of home } \\
\hline Self-owned & 1091 & 92 \\
\hline Rented & 90 & 8 \\
\hline \multicolumn{3}{|l|}{ Number of household members } \\
\hline$\leq 4$ & 254 & 21 \\
\hline $5-8$ & 586 & 50 \\
\hline$\geq 9$ & 341 & 29 \\
\hline
\end{tabular}

${ }^{*}$ For details see pages $10-11$ of [12].

Table 2 provides the WASH characteristics of the households included in the study. Figure 2a depicts the community perceptions of the causes of diarrhea and Figure $2 b$ depicts the community perceptions of various effective treatments (Supplementary Table S1). 
Table 2. Water sanitation and hygiene-related characteristics of 1181 the households.

\begin{tabular}{|c|c|c|}
\hline Water Sanitation and Hygiene Related Characteristics & $n=1181$ & $\%$ \\
\hline \multicolumn{3}{|l|}{ Water treatment } \\
\hline \multicolumn{3}{|l|}{ Drinking water source * } \\
\hline Hand-pump & 709 & 60 \\
\hline Bore well & 683 & 58 \\
\hline Tap (municipal supply) & 294 & 25 \\
\hline \multicolumn{3}{|l|}{ Storage practices * } \\
\hline Roof-top storage & 242 & 20 \\
\hline Ground storage & 1181 & 100 \\
\hline \multicolumn{3}{|l|}{ Drinking water storage containers * } \\
\hline Earthenware pot (Matka/Ghada) & 1181 & 100 \\
\hline Buckets & 557 & 47 \\
\hline Plastic cans & 298 & 25 \\
\hline \multicolumn{3}{|l|}{ Frequency of cleaning ground water containers } \\
\hline Daily & 779 & 66 \\
\hline Every 2 nd-3rd day & 250 & 21 \\
\hline Weekly or more & 154 & 13 \\
\hline \multicolumn{3}{|l|}{ Do you treat water before drinking? } \\
\hline No & 283 & 24 \\
\hline Yes & 898 & 76 \\
\hline Filtration using cloth & 839 & 71 \\
\hline Coagulation, flocculation, and sedimentation (by alum) & 43 & 4.4 \\
\hline Boiling for $20 \mathrm{~min}$ & 16 & 1.6 \\
\hline \multicolumn{3}{|l|}{ Sanitation } \\
\hline \multicolumn{3}{|l|}{ Toilet constructed in household } \\
\hline Yes & 1100 & 93 \\
\hline Toilet used by adults & 1080 & 91 \\
\hline Toilet used by children & 276 & 23 \\
\hline \multicolumn{3}{|l|}{ Household waste } \\
\hline Thrown on streets & 1050 & 89 \\
\hline Burnt & 83 & 7 \\
\hline Collected and disposed (municipal facility) & 48 & 4 \\
\hline \multicolumn{3}{|l|}{ Hand washing done by mothers/caregivers } \\
\hline After cleaning child's feces & 1155 & 98 \\
\hline After toilet & 1153 & 98 \\
\hline After cooking & 960 & 81 \\
\hline After cleaning child's urine & 675 & 77 \\
\hline Before feeding child & 603 & 51 \\
\hline To clean visible dirt & 558 & 47 \\
\hline Before cooking & 352 & 30 \\
\hline After cleaning nose/mouth & 319 & 27 \\
\hline
\end{tabular}

${ }^{*}$ Numbers and percentages totaling more than 1181 and $100 \%$, respectively due to multiple responses. 

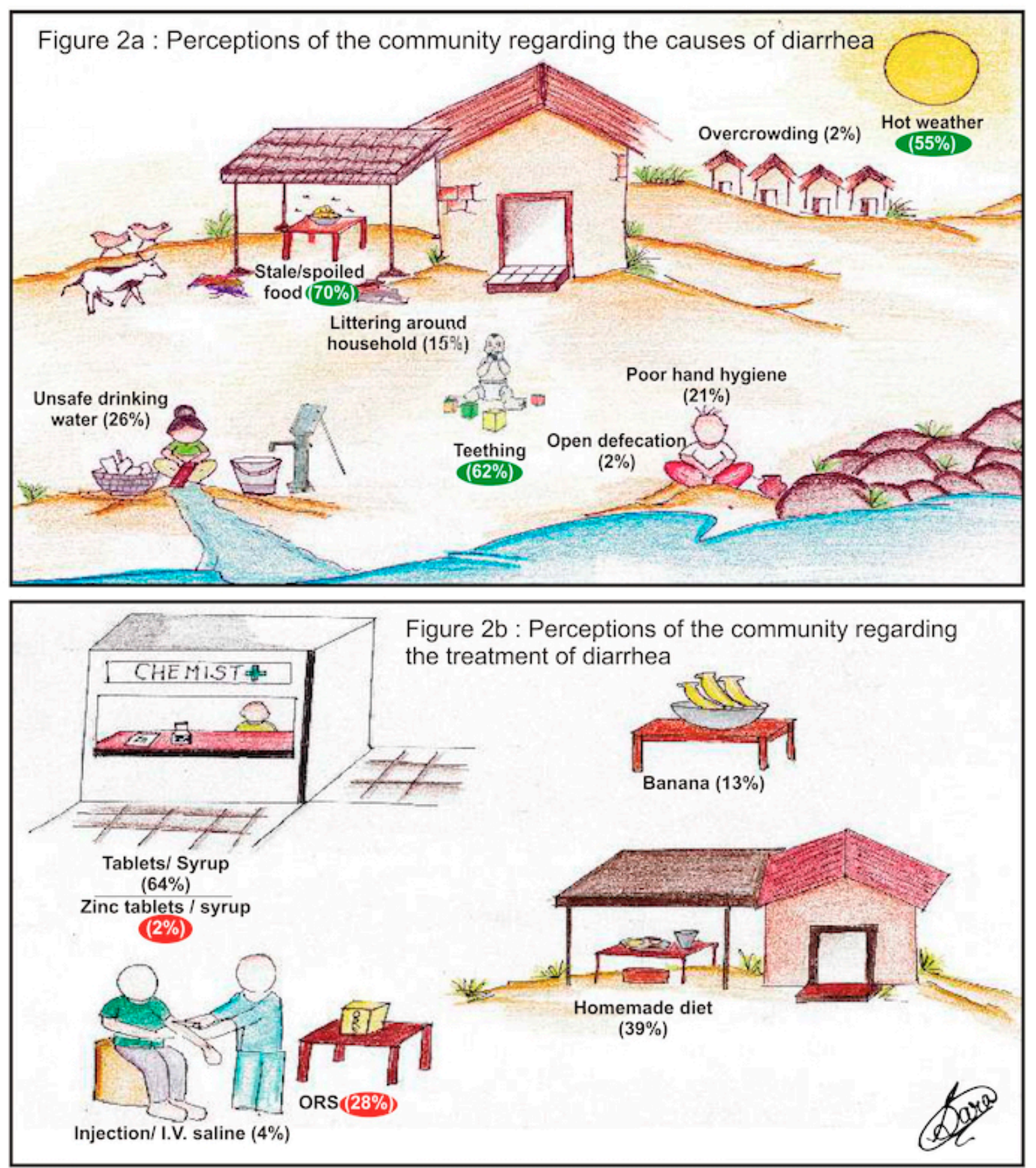

Figure 2. Perceptions of 1571 mothers regarding cause (a) and treatment of diarrhea (b) (Table S1 provides details in tabular form).

\section{Treatment Given to Children for the Last Episode of Diarrhea}

Out of the total 1571 children, 521(33\%) children were reported to have acute diarrhea. Among the 521 children having diarrhea, a total of 510 (98\%) children received some treatment (Table 3). The different antibiotics prescribed to children during the last episode of diarrhea are shown in Figure 3. The most common antibiotic prescribed was ofloxacin $(n=104 ; 23 \%)$, followed by metronidazole $(n=72$; $16 \%)$, and the most commonly prescribed combination of antibiotics was ofloxacin with ornidazole $(n=175 ; 39 \%)$, followed by norfloxacin with ornidazole $(n=28 ; 6 \%)$. Overall antibiotic combinations were prescribed to $54 \%$ of children $(n=227)$. Among the children who received treatment $(n=423)$, $83 \%$ received antibiotics, $29 \%$ received ORS, and only $10 \%$ received zinc. Other drugs prescribed 
were probiotics $(25 \%)$, paracetamol (18\%), loperamide (16\%), dicyclomine $(7 \%)$, and ondansetron (5\%). Figure 3 provides the details of the antibiotics given to children with diarrhea.

Table 3. Feeding practice and treatment received by 521 (33\%) children out of the total 1571 children during the last episode of diarrhea.

\begin{tabular}{|c|c|c|}
\hline Categorical Variables & $n=521$ & $\%$ \\
\hline \multicolumn{3}{|l|}{ Feeding Practices * } \\
\hline Continued breastfeeding & 249 & 48 \\
\hline Top milk & 270 & 52 \\
\hline Tea & 230 & 44 \\
\hline Homemade diet & 314 & 60 \\
\hline Mashed food/fruit & 224 & 43 \\
\hline Heard about ORS & 173 & 33 \\
\hline \multicolumn{3}{|l|}{ Where to get ORS? } \\
\hline Health care workers & 388 & 74 \\
\hline Pharmacy store & 29 & 6 \\
\hline Don't know & 104 & 20 \\
\hline Heard about zinc & 62 & 12 \\
\hline \multicolumn{3}{|l|}{ Where to get zinc? } \\
\hline Health care workers & 177 & 34 \\
\hline Pharmacy store & 29 & 6 \\
\hline Don't know & 315 & 60 \\
\hline \multicolumn{3}{|l|}{ Treatment practices } \\
\hline No treatment & 11 & 2 \\
\hline Self-treatment only & 155 & 30 \\
\hline Self-treatment with ORS & 28 & 18 \\
\hline Self-treatment with left over medicines & 123 & 79 \\
\hline Zinc tablet/ syrup & 6 & 4 \\
\hline Homemade solutions & 34 & 22 \\
\hline Treatment at healthcare facility & 485 & 93 \\
\hline Government setting & 83 & 17 \\
\hline Private setting & 339 & 70 \\
\hline Formal health care provider & 106 & 31 \\
\hline Informal healthcare provider & 233 & 69 \\
\hline Medical store & 63 & 13 \\
\hline Both self and healthcare facility & 130 & 25 \\
\hline Received any treatment & 510 & 98 \\
\hline Received an antibiotic & 423 & 83 \\
\hline Received ORS & 150 & 29 \\
\hline Received zinc tablets/syrups & 54 & 11 \\
\hline
\end{tabular}

${ }^{*}$ Numbers and percentages totaling more than 521 and $100 \%$, respectively due to multiple responses. 


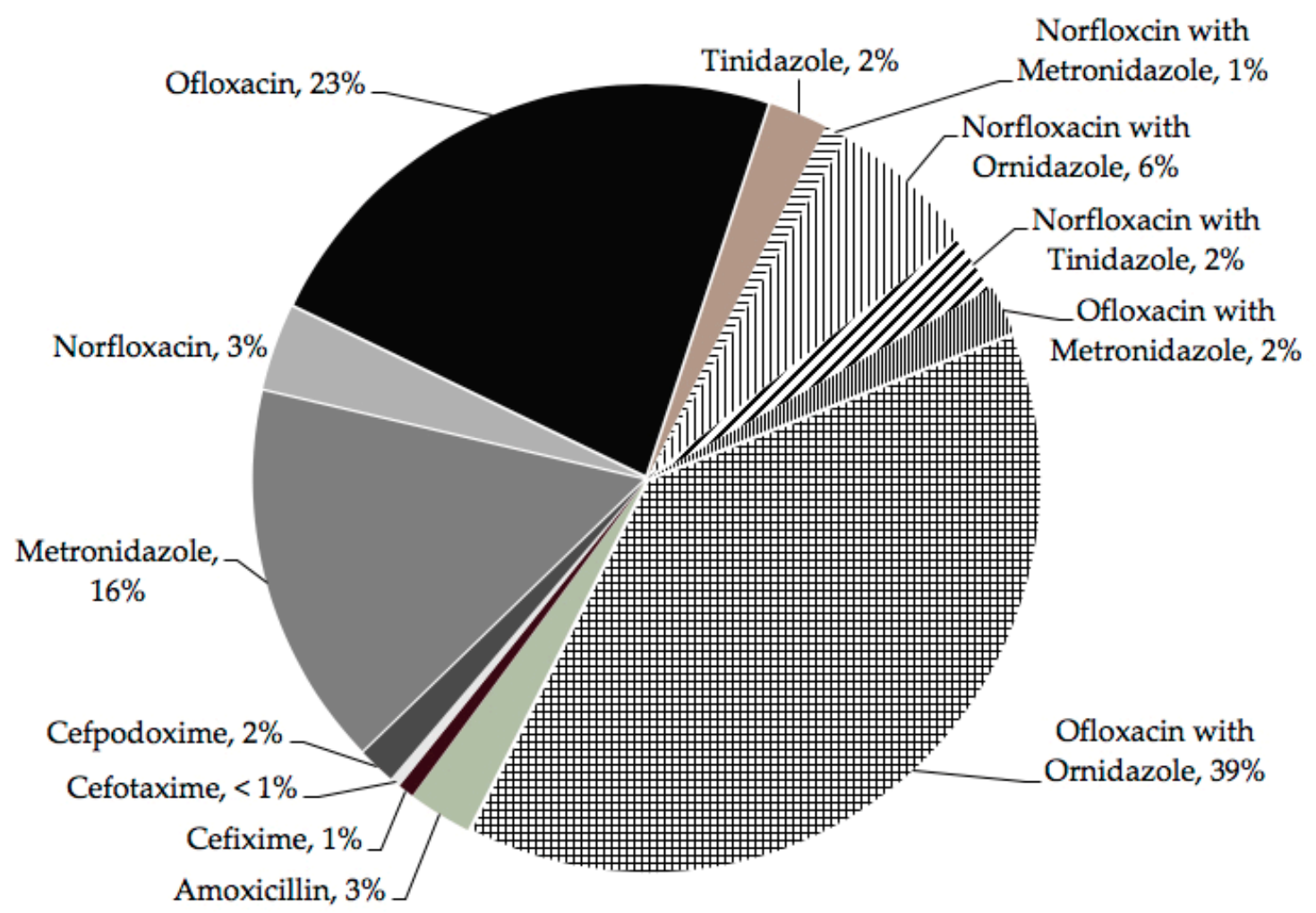

Figure 3. Antibiotics prescribed to the children with diarrhea during the last episode of diarrhea.

\section{Discussion}

The study included a total of 1571 children residing in 1181 households located in both rural and urban areas of Ujjian. The mean age of children included in the study was 2.08 years. The WASH-related characteristics revealed that most $(60 \%)$ households used hand-pump as a drinking water source, and most $(71 \%)$ households filtered water before storage using a simple cloth. Many $(93 \%)$ households had a toilet built in the household, but only $23 \%$ of children used them. Most $(89 \%)$ households dumped their household waste on the streets. Almost all (98\%) mothers claimed to wash hands after toilet use, but only $30 \%$ did so before cooking. Most $(70 \%)$ mothers perceived that stale or spoiled food followed by teething $(62 \%)$ and hot weather $(55 \%)$ were the most common causes of diarrhea. For the treatment of diarrhea, the perception was that some form of tablets/syrups were prescribed $(64 \%)$, children given homemade diet (35\%), and bananas were perceived to be beneficial by $13 \%$ of mothers. Nearly half the mothers continued breast-feeding during the diarrheal episode; however, only 33\% and $12 \%$ of the mothers had heard about ORS and zinc, respectively. Of the children that received treatment, antibiotics were prescribed in $83 \%$ and ORS and zinc in $29 \%$ and $11 \%$, respectively.

In the present study, the major cause of diarrhea perceived by the community was stale food, followed by teething and hot weather. Studies conducted in Eastern Sudan [16], Saudi Arabia [17], and Nepal [18] have also reported stale food and teething as the major risk factors for diarrhea, as identified by the community. In the three aforementioned studies, hygiene and sanitation-related risk factors including, poor hand washing practices, open-air defecation, and littering around the household were perceived as less important causes of childhood diarrhea by the community [16-18], which is similar to the present study.

In India, diarrhea seasonality is well known $[3,19]$. Rotavirus infections present two seasonal peaks in India, one in winter and the other in summer; the increase in temperature reduces the transmission of rotavirus infections [20]. In summer, the limited potable water supply poses potential public health risks for diarrhea [3]. The scarcity of potable water during hot Indian summers and the 
peaking of diarrhea during summers probably shapes the community's perception that hot weather is an important risk factor for diarrhea.

The community perceived unsafe drinking water as an important cause of diarrhea $(26 \%)$. The majority of households that reported household water treatment used simple filtration of drinking water through a cloth. According to World Health Organization and United Nations International Children's Emergency Fund's core questions on drinking water and sanitation for household surveys [21], simple filtration is classified as an inadequate method; however, it has been shown to be effective in protecting against Vibrio cholera infections in 65 villages in Bangladesh, in which simple "sari" cloth was used for water filtration [22]. Most households in the study area had access to safe drinking water sources. Fecal contamination of drinking water remains the most important cause of diarrhea globally, although this was not specifically tested in the present study [23]. Contamination of drinking water usually occurs not at the source but mostly at the household level [24]. Littering around the household can play a major role, as perceived by the community. The nonuse of toilets, even when available within households, is a problem that can be addressed through behavior change communication (BCC) and has been reported in rural areas of Odisha, India [25] and urban areas of Bhopal in MP [26]. Other resource-poor countries, such as Bangladesh [27], Zambia [28], and Ethiopia [29], also show low utilization rates of latrines.

In this study, the majority (64\%) of mothers/caregivers (Figure $2 \mathrm{~b}$ ) perceived that syrups and tablets provided by healthcare providers are effective treatments for diarrhea. The knowledge of ORS and its benefits for childhood diarrhea was poor in our settings (28\%, Figure $2 b)$, which is in contrast to the findings of other studies conducted in India [9-11]. In our setting, the zinc use rate of $2 \%$ was much lower than the national average rate of approximately 30\% [3]. Moreover, there was a severe lack of knowledge of zinc use among mothers in India and other resource-poor countries [30-32]. This lack of knowledge and low acceptance for ORS and zinc use among community members/mothers are prevalent despite the fact that ORS and zinc tablets are offered free of cost by the government health sector and are offered at the doorstep by front-line healthcare workers in India. However, the increased use of homemade fluids and bananas is encouraging and should be promoted [33]. A high proportion of antibiotic prescriptions, especially the irrational combination of antibiotics, (most commonly ofloxacin with ornidazole) for diarrhea has been documented and is a major public health problem in India [6]. High use of antibiotics for diarrhea in the study settings warrants specific interventions for healthcare workers.

\section{Methodological Considerations}

In the present study, we attempted to retrospectively ascertain drug use mainly ORS and zinc and antibiotics through interviews, which may be subject to bias due to differential recall. ORS and zinc use recall were better than antibiotic recall as participants could recognize ORS and zinc easily. This kind of recall bias would underestimate antibiotic use more compared to ORS and zinc use.

\section{Conclusions}

Childhood diarrhea is a major public health concern globally and in India. Effective interventions are known but are rarely implemented in resource-limited settings and settings with fragmented healthcare systems, similar to the settings in this study. The results of this study provided insights into community awareness of causes of diarrhea, its treatment, and other WASH-related variables. The results of the present study will help the design of content-specific interventions at the community level for the mothers, children, and healthcare workers.

Supplementary Materials: The following are available online at http://www.mdpi.com/1660-4601/16/9/1646/s1, Table S1: Community perception about cause and treatment of diarrhea.

Author Contributions: Conceptualization-A.P. and V.D.; Methodology-A.P.; Validation-A.P., D.B., J.J., A.M. and V.D.; Formal Analysis-A.P. and A.M.; Investigation-A.P., A.M., D.B., J.J., and V.D.; Resources-A.P.; Data Curation-A.P., L.M., A.M. and V.D.; Writing and original draft preparation-A.P.; Writing, review \& editing, A.P., 
A.M. and V.D.; Visualization-A.P., A.M. and V.D; Supervision-A.P.; Project Administration-A.P.; Funding Acquisition-A.P., and V.D.

Funding: This research was funded by the Indian Council of Medical Research (ICMR) New Delhi, India (grant number 70/1/2017-BMS/DUR).

Acknowledgments: Authors would like to acknowledge R D Gardi Medical College, Ujjain, India for their support in the data collection of this study.

Conflicts of Interest: The authors declare no conflict of interest.

\section{References}

1. UNICEF; WHO. End Preventable Deaths: Global Action Plan for Prevention and Control of Pneumonia and Diarrhoea; World Health Organization: Lyon, France, 2013; Available online: http://apps.who.int/iris/bitstream/handle/ 10665/79200/9789241505239_eng.pdf;jsessionid=837AEC1288C76D2368F1E8F8DAB86B55? sequence=1 (accessed on 29 December 2018).

2. Global Burden of Disease Collaborators. Estimates of the global, regional, and national morbidity, mortality, and aetiologies of diarrhoea in 195 countries: A systematic analysis for the global burden of disease study 2016. Lancet Infect. Dis. 2018, 18, 1211-1228. [CrossRef]

3. Ganguly, E.; Sharma, P.K.; Bunker, C.H. Prevalence and risk factors of diarrhea morbidity among under-five children in India: A systematic review and meta-analysis. Indian J. Child Health 2015, 2, 152-160.

4. Ram, U.; Jha, P.; Ram, F.; Kumar, S.; Awasthi, S.; Shet, A.; Padera, J.; Nansukusa, S.; Kumar, R. Neonatal, 1-59 month, and under-5 mortality in 597 Indian districts, 2001 to 2012: Estimates from national demographic and mortality surveys. Lancet Glob. Health 2013, 1, e219-e226. [CrossRef]

5. Walker, C.L.; Rudan, I.; Liu, L.; Nair, H.; Theodoratou, E.; Bhutta, Z.A.; O’Brien, K.L.; Campbell, H.; Black, R.E. Global burden of childhood pneumonia and diarrhoea. Lancet 2013, 381, 1405-1416. [CrossRef]

6. Pathak, D.; Pathak, A.; Marrone, G.; Diwan, V.; Lundborg, C.S. Adherence to treatment guidelines for acute diarrhoea in children up to 12 years in Ujjain, India-A cross-sectional prescription analysis. BMC Infect. Dis. 2011, 11, 32. [CrossRef]

7. Lakshminarayanan, S.; Jayalakshmy, R. Diarrheal diseases among children in India: Current scenario and future perspectives. J. Nat. Sci. Biol. Med. 2015, 6, 24-28. [CrossRef] [PubMed]

8. Bhutta, Z.A.; Das, J.K.; Walker, N.; Rizvi, A.; Campbell, H.; Rudan, I.; Black, R.E.; Lancet, D.; Pneumonia Interventions Study Group. Interventions to address deaths from childhood pneumonia and diarrhoea equitably: What works and at what cost? Lancet 2013, 381, 1417-1429. [CrossRef]

9. Kadam, D.M.; Hadaye, R.; Pandit, D. Knowledge and practices regarding oral rehydration therapy among mothers in rural area of Vasind, India. Nepal. Med. Coll. J. 2013, 15, 110-112. [PubMed]

10. Bhatia, V.; Swami, H.M.; Bhatia, M.; Bhatia, S.P. Attitude and practices regarding diarrhoea in rural community in Chandigarh. Indian J. Pediatr. 1999, 66, 499-503. [CrossRef] [PubMed]

11. Datta, V.; John, R.; Singh, V.P.; Chaturvedi, P. Maternal knowledge, attitude and practices towards diarrhea and oral rehydration therapy in rural Maharashtra. Indian J. Pediatr. 2001, 68, 1035-1037. [CrossRef]

12. Ujjain district. Office of the Registrar General and Census Commissioner, Ministry of Home Affairs, Government of India, New Delhi, 2011. Available online: http://www.censusindia.gov.in/2011census/dchb/ DCHB_A/23/2318_PART_A_DCHB_UJJAIN.pdf (accessed on 29 December 2018).

13. National Family Health Survey-4 (NFHS 4). District Fact Sheet, Ujjain, Madhya Pradesh, Ministry of Health and Family Welfare; Ministry of Health and Family Welfare, Government of India: New Delhi, India, 2016; pp. 105-116. Available online: http://rchiips.org/NFHS/FCTS/MP/MP_FactSheet_435_Ujjain.pdf (accessed on 29 December 2018).

14. Rowe, A.K.; Lama, M.; Onikpo, F.; Deming, M.S. Design effects and intraclass correlation coefficients from a health facility cluster survey in Benin. Int. J. Qual. Health Care 2002, 14, 521-523. [CrossRef]

15. Rattray, J.; Jones, M.C. Essential elements of questionnaire design and development. J. Clin. Nurs. 2007, 16, 234-243. [CrossRef]

16. El Bushra, H.A.; Tigerman, N.S.; El Tom, A.R. Perceived causes and traditional treatment of diarrhoea by mothers in eastern Sudan. Ann. Trop. Paediatr. 1988, 8, 135-140. [CrossRef]

17. Bella, H.; Ai-Freihi, H.; El-Mousan, M.; Danso, K.T.; Sohaibani, M.; Khazindar, M.S. Knowledge, attitudes and practices related to diarrhoea in eastern province, Saudi Arabia. J. Fam. Community Med. 1994, 1, 40-44. 
18. Stapleton, M.C. Diarrhoeal diseases: Perceptions and practices in Nepal. Soc. Sci. Med. 1989, $28,593-604$. [CrossRef]

19. Gladstone, B.P.; Das, A.R.; Rehman, A.M.; Jaffar, S.; Estes, M.K.; Muliyil, J.; Kang, G.; Bose, A. Burden of illness in the first 3 years of life in an indian slum. J. Trop. Pediatr. 2010, 56, 221-226. [CrossRef]

20. Sarkar, R.; Kang, G.; Naumova, E.N. Rotavirus seasonality and age effects in a birth cohort study of southern India. PLOS ONE 2013, 8, e71616. [CrossRef]

21. WHO/UNICEF Core Questions on Drinking Water and Sanitation for Household Surveys. World Health Organization and United Nations Children's Fund: Geneva, Switzerland; New York, NY, USA, 2004; Available online: https://www.who.int/mediacentre/news/releases/2017/launch-version-report-jmp-watersanitation-hygiene.pdf (accessed on 29 December 2018).

22. Huq, A.; Yunus, M.; Sohel, S.S.; Bhuiya, A.; Emch, M.; Luby, S.P.; Russek-Cohen, E.; Nair, G.B.; Sack, R.B.; Colwell, R.R. Simple sari cloth filtration of water is sustainable and continues to protect villagers from cholera in Matlab, Bangladesh. MBio 2010, 1, e00034-10. [CrossRef]

23. Bain, R.; Cronk, R.; Hossain, R.; Bonjour, S.; Onda, K.; Wright, J.; Yang, H.; Slaymaker, T.; Hunter, P.; Pruss-Ustun, A.; et al. Global assessment of exposure to faecal contamination through drinking water based on a systematic review. Trop. Med. Int. Health 2014, 19, 917-927. [CrossRef]

24. Kundu, A.; Smith, W.A.; Harvey, D.; Wuertz, S. Drinking water safety: Role of hand hygiene, sanitation facility, and water system in semi-urban areas of India. Am. J. Trop. Med. Hyg. 2018, 99, 889-898. [CrossRef]

25. Sinha, A.; Nagel, C.L.; Schmidt, W.P.; Torondel, B.; Boisson, S.; Routray, P.; Clasen, T.F. Assessing patterns and determinants of latrine use in rural settings: A longitudinal study in Odisha, India. Int. J. Hyg. Environ. Health 2017, 220, 906-915. [CrossRef] [PubMed]

26. Biran, A.; Jenkins, M.W.; Dabrase, P.; Bhagwat, I. Patterns and determinants of communal latrine usage in urban poverty pockets in Bhopal, India. Trop. Med. Int. Health 2011, 16, 854-862. [CrossRef]

27. Akter, T.; Ali, A.R.; Dey, N.C. Transition overtime in household latrine use in rural Bangladesh: A longitudinal cohort study. BMC Public Health 2014, 14, 721. [CrossRef]

28. Thys, S.; Mwape, K.E.; Lefevre, P.; Dorny, P.; Marcotty, T.; Phiri, A.M.; Phiri, I.K.; Gabriel, S. Why latrines are not used: Communities' perceptions and practices regarding latrines in a Taenia solium endemic rural area in eastern Zambia. PLoS Negl. Trop. Dis. 2015, 9, e0003570. [CrossRef]

29. Awoke, W.; Muche, S. A cross sectional study: Latrine coverage and associated factors among rural communities in the district of Bahir Dar Zuria, Ethiopia. BMC Public Health 2013, 13, 99. [CrossRef]

30. Zwisler, G.; Simpson, E.; Moodley, M. Treatment of diarrhea in young children: Results from surveys on the perception and use of oral rehydration solutions, antibiotics, and other therapies in India and Kenya. J. Glob. Health 2013, 3, 010403. [CrossRef]

31. Shah, M.S.; Ahmad, A.; Khalique, N.; Afzal, S.; Ansari, M.A.; Khan, Z. Home-based management of acute diarrhoeal disease in an urban slum of Aligarh, India. J. Infect. Dev. Ctries. 2012, 6, 137-142. [CrossRef]

32. Joseph, N.; Suvarna, P.; Hariharan Bharadwaj, S.; Dhanush, K.S.; Raeesa, F.; Mohamed Jasir, K.K.; Joseph, N.; Kotian, S.M.; Rai, S. Prevalence, risk factors and treatment practices in diarrhoeal diseases in south India. Environ. Health Prev. Med. 2016, 21, 248-257. [CrossRef] [PubMed]

33. Rabbani, G.H.; Larson, C.P.; Islam, R.; Saha, U.R.; Kabir, A. Green banana-supplemented diet in the home management of acute and prolonged diarrhoea in children: A community-based trial in rural Bangladesh. Trop. Med. Int. Health 2010, 15, 1132-1139. [CrossRef]

(C) 2019 by the authors. Licensee MDPI, Basel, Switzerland. This article is an open access article distributed under the terms and conditions of the Creative Commons Attribution (CC BY) license (http://creativecommons.org/licenses/by/4.0/). 